\title{
Comparison of Distal Limb Warming With Fluidotherapy and Warm Water Immersion for Mild Hypothermia Rewarming
}

\author{
Parveen Kumar, MPT, MSc; Gerren K. McDonald, BA, MSc; Radhika Chitkara, MPT, MSc; \\ Alan M. Steinman, MD, MPH; Phillip F. Gardiner, MPE, PhD; Gordon G. Giesbrecht, BTh, PhD \\ From the Laboratory for Exercise and Environmental Medicine, Faculty of Kinesiology and Recreation Management, University of Manitoba, \\ Winnipeg, Manitoba, Canada (all authors); and the Gupta Faculty of Kinesiology and Applied Health, University of Winnipeg, Winnipeg, \\ Manitoba, Canada (Mr McDonald).
}

Objective.-The purpose of the study was to determine the effectiveness of Fluidotherapy rewarming through the distal extremities for mildly hypothermic, vigorously shivering subjects. Fluidotherapy is a dry heat modality in which cellulose particles are suspended by warm air circulation.

Methods.-Seven subjects ( 2 female) were cooled on 3 occasions in $8^{\circ} \mathrm{C}$ water for 60 minutes, or to a core temperature of $35^{\circ} \mathrm{C}$. They were then dried and rewarmed in a seated position by 1) shivering only; 2) Fluidotherapy applied to the distal extremities (46 $\pm 1{ }^{\circ} \mathrm{C}$, mean $\pm \mathrm{SD}$ ); or 3 ) water immersion of the distal extremities $\left(44 \pm 1^{\circ} \mathrm{C}\right.$ ). The order of rewarming followed a balanced design. Esophageal temperature, skin temperature, heart rate, oxygen consumption, and heat flux were measured.

Results.-The warm water produced the highest rewarming rate, $6.1^{\circ} \mathrm{C} \cdot \mathrm{h}^{-1}, 95 \% \mathrm{CI}$ : $5.3-6.9$, compared with Fluidotherapy, $2.2^{\circ} \mathrm{C} \cdot \mathrm{h}^{-1}, 95 \% \mathrm{CI}$ : $1.4-3.0$, and shivering only, $2.0^{\circ} \mathrm{C} \cdot \mathrm{h}^{-1}, 95 \% \mathrm{CI}$ : 1.2-2.8. The Fluidotherapy and warm water conditions increased skin temperature and inhibited shivering heat production, thus reducing metabolic heat production $(166 \pm 42 \mathrm{~W}$ and $181 \pm 45 \mathrm{~W}$, respectively), compared with shivering only $(322 \pm 142 \mathrm{~W})$. Warm water provided a significantly higher net heat gain $(398.0 \pm 52 \mathrm{~W})$ than shivering only $(288.4 \pm 115 \mathrm{~W})$.

Conclusions.-Fluidotherapy was not as effective as warm water for rewarming mildly hypothermic subjects. Although Fluidotherapy is more portable and technically simpler, it provides a lower rate of rewarming that is similar to shivering only. It does help decrease shivering heat production, lowering energy expenditure and cardiac work, and could be considered in a hospital setting, if convenient.

Key words: shivering heat production, thermal core, effective perfused mass, afterdrop, hospital treatment

\section{Introduction}

Many wilderness and adventure activities present the risk of cold exposure and accidental hypothermia. In the United States, approximately 1500 hypothermic patients visit an emergency department (ED) each year. ${ }^{1}$ Patients with mild to moderate hypothermia are generally warmed externally, namely, with warm water bottles "in the field" 2 or forced air warming "in the ED."3 These methods generally increase skin temperature and reduce shivering heat production, resulting in afterdrop and rewarming rates similar to those of shivering (control)

Corresponding author: Gordon Giesbrecht, $\mathrm{PhD}, 102$ Frank Kennedy Building, University of Manitoba, Winnipeg, MB R3T 2N2, Canada (e-mail: giesbrec@cc.umanitoba.ca). protocols; shivering inhibition reduces metabolic energy use, cardiac work, and discomfort. ${ }^{3}$

Whole body warm water immersion is contraindicated as it increases the risk of cardiovascular collapse. ${ }^{4}$ However, immersing only the distal extremities in $45^{\circ} \mathrm{C}$ water safely decreased afterdrop and almost tripled the core rewarming rate to $\left(9.9^{\circ} \mathrm{C} \cdot \mathrm{h}^{-1}\right)$ compared with other external methods. ${ }^{5}$ Limitations of this method include water spillage, specialized temperature control equipment, space requirements, and a fixed location.

Fluidotherapy, a common physiotherapy heating modality for distal extremities, is a potential alternate distal extremity rewarming method. This modality consists of a warming chamber with openings for distal arms 
and legs. ${ }^{6}$ Cellulose particles, which form a fluidized bed, are circulated around the extremities by hot air. Fluidotherapy $\left(48^{\circ} \mathrm{C}-49^{\circ} \mathrm{C}\right)$ provided three times greater heat transfer to copper bars, ${ }^{6}$ and warmed muscle tissue by $20 \%$ to $50 \%$ more,,$^{7}$ than warm water $\left(39^{\circ} \mathrm{C}-41^{\circ} \mathrm{C}\right)$ or wax baths $\left(52^{\circ} \mathrm{C}-55^{\circ} \mathrm{C}\right)$. This increased heat transfer may result from tolerance of higher temperatures of the fluidized bed compared with warm water, convective air movement, and high thermal conductance of cellulose particles. ${ }^{6,7}$ Higher temperature tolerance occurs because the cellulose particles overstimulate skin thermoreceptors and mechanoreceptors, consequently decreasing pain sensitivity. ${ }^{6}$ Moreover, dry heat minimizes thermal irritation at high temperatures. ${ }^{6}$ This method also provides more heat than traditional forced air warming ${ }^{3}$ owing to a combination of higher air temperature $\left(\sim 5^{\circ} \mathrm{C}\right)$ and thermal conductance of cellulose particles. Potential practical benefits of Fluidotherapy (compared with distal limb immersion) are that it is commercially available, technically simple, programmable, requires less space, is portable, and avoids water spillage.

The purpose of this study was to evaluate Fluidotherapy warming of all distal extremities in mildly hypothermic subjects. We hypothesized that Fluidotherapy $\left(50^{\circ} \mathrm{C}\right)$ would provide more heat, reduce shivering and afterdrop, and increase core rewarming compared with extremity immersion in warm water (at $45^{\circ} \mathrm{C}$ ) and shivering only.

\section{Methods}

\section{SUBJECTS}

Physically active volunteers were studied after screening for any medical conditions and giving written informed consent. The Biomedical Research Ethics Board at the University of Manitoba approved the protocol.

\section{INSTRUMENTATION}

A single-channel electrocardiogram and heart rate were monitored continuously, and core temperature was measured by a thermocouple inserted into the esophagus $\left(\mathrm{T}_{\mathrm{es}}\right)$ to the level of the heart. ${ }^{8}$ Skin temperature $\left(\mathrm{T}_{\text {skin }}\left[{ }^{\circ} \mathrm{C}\right]\right)$ and cutaneous heat flux ( $\mathrm{HF}\left[\mathrm{W} \cdot \mathrm{m}^{-2}\right]$ ) were measured at 12 sites with thermal flux transducers (Concept Engineering Old Saybrook, CT). Sites were forehead, anterior and posterior torso, upper arm, proximal and distal forearm, hand, anterior and posterior thigh, and proximal and distal lower leg and foot. Positive values indicate heat loss from the skin. Oxygen consumption $\left(\mathrm{VO}_{2}\left[\mathrm{~L} \cdot \mathrm{min}^{-1}\right]\right)$ and minute ventilation $\left(\mathrm{V}_{\mathrm{E}}\left[\mathrm{L} \cdot \min ^{-1}\right]\right)$ were determined with an open-circuit method (Vmax 229, SensorMedics Yorba Linda, CA).

\section{REWARMING METHODS}

Because subjects were seated in a head-down position during Fluidotherapy and water rewarming, they also assumed this position in the shivering condition to eliminate any possible effects of posture.

For the shivering only (control) rewarming method, after being seated, subjects leaned forward, resting their head on a head support, and were then covered with a sleeping bag. In this condition, the subject rewarmed spontaneously by endogenous shivering thermogenesis.

For the Fluidotherapy rewarming method, a chamber (model 115D, DJO Canada, Mississauga, Ontario) $86 \mathrm{~cm}$ long, $47 \mathrm{~cm}$ wide, and $84 \mathrm{~cm}$ high was used. New sleeves were created for the top portals of the chamber to allow insertion of all four distal extremities (ie, lower legs up to the knee and forearms up to the elbow). The unit was preheated to $45^{\circ} \mathrm{C}$ at $35 \%$ air speed. After limb insertion, the unit was then turned on at $45^{\circ} \mathrm{C}$ and $100 \%$ air speed. The subjects were then covered with a sleeping bag. Unit temperature was adjusted during the rewarming period based on the subject's tolerance (maximum, $50^{\circ} \mathrm{C}$ ) (Figure 1).

For the warm water method, the goal was to maintain water temperature at $45 \pm 1{ }^{\circ} \mathrm{C}$; this would have the effect of decreasing the temperature advantage of Fluidotherapy, but we wanted to test both conditions at their maximum tolerable temperature and, therefore, rewarming effectiveness. After immersion, subjects were hoisted into the warm water tank and positioned with lower legs immersed to knee level. They then leaned forward resting their head on the front support, immersing their forearms up to the level of elbow (ie, same level as Fluidotherapy immersion), and were covered with a sleeping bag (Figure 1).

\section{PROTOCOL}

Each subject was cooled on three different occasions separated by at least 48 hours, at the same time of day. Both female subjects were consistently studied in the follicular phase. After 10 minutes of baseline measurements, subjects were immersed up to the sternal notch in an approximately $21^{\circ} \mathrm{C}$ stirred water bath. Water temperature was then lowered to $8^{\circ} \mathrm{C}$ over 10 minutes by the addition of ice. Subjects remained in the water until either $\mathrm{T}_{\mathrm{es}}$ reached $35^{\circ} \mathrm{C}$ or 60 minutes elapsed. Subjects were towel dried and then rewarmed by one of the three treatment methods. The order of rewarming methods was randomly chosen and followed a balanced design. Treatment continued for 60 minutes or until $\mathrm{T}_{\mathrm{es}}$ rose to $37^{\circ} \mathrm{C}$, followed by warm water immersion $\left(40^{\circ} \mathrm{C}-42^{\circ} \mathrm{C}\right)$ until the $\mathrm{T}_{\text {es }}$ rose to $37^{\circ} \mathrm{C}$ (if necessary) or the subject wished to exit. 

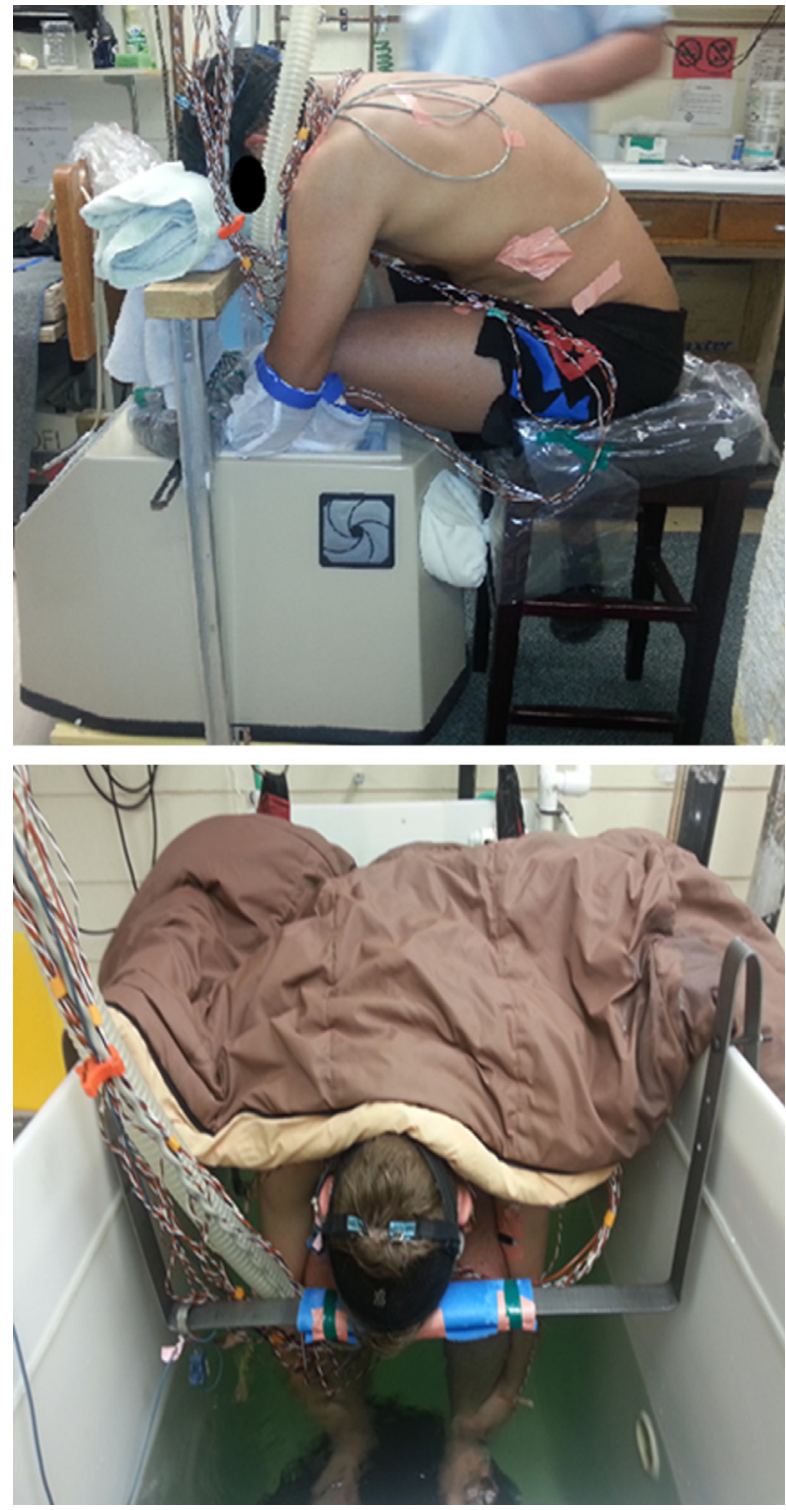

Figure 1. Distal extremity rewarming with Fluidotherapy (top panel) and warm water immersion (bottom panel). Distal extremities are exposed up to the elbows and knees. Note: the sleeping bag that is normally draped over the subject during Fluidotherapy was removed for easier visualization.

After their last trial, subjects were asked to compare the three rewarming methods based on warmth, comfort, and preference. They were also asked to provide any feedback related to discomfort associated with any of the methods.

\section{DATA ANALYSIS}

Rate of core cooling $\left({ }^{\circ} \mathrm{C} \cdot \mathrm{h}^{-1}\right)$ was calculated for the last 20 minutes of cold water immersion. Afterdrop $\left({ }^{\circ} \mathrm{C}\right)$ was calculated as the difference between $\mathrm{T}_{\mathrm{es}}$ on exit from the cold water and its nadir. Length of the afterdrop period (minutes) was calculated from the time of exit from the cold water until $\mathrm{T}_{\mathrm{es}}$ returned to the original exit $\mathrm{T}_{\mathrm{es}}$. Rate of rewarming $\left({ }^{\circ} \mathrm{C} \cdot \mathrm{h}^{-1}\right)$ was calculated from the nadir to 35 minutes of rewarming. Distal extremity skin temperature $\left(\mathrm{T}_{\text {skinDistExt }}\left[{ }^{\circ} \mathrm{C}\right]\right)$ and distal extremity heat flux $\left(\mathrm{HF}_{\text {DistExt }}[\mathrm{W}]\right)$ were calculated from area-weighted average of temperatures and a sum of the absolute heat flux values (6 sites). Total skin temperature $\left(\mathrm{T}_{\text {skTotal }}\right)$ and total heat flux $\left(\mathrm{HF}_{\text {Total }}\right)$ were calculated using all 12 sites.

Net heat balance was calculated by subtracting the respiratory heat loss $(\mathrm{RHL}[\mathrm{W}]=0.09 * \mathrm{M})$ and total cutaneous heat flux from the metabolic heat production (M $\left.[\mathrm{W}]=\mathrm{Vo}_{2} * 69.7 *[4.686+([0.83-0.707] * 1.232)]\right)$. Net heat balance $(\mathrm{W})=\mathrm{M}-\mathrm{RHL}-\mathrm{HF}_{\text {Total }}$. For heat flux, positive values indicate heat loss from the skin. For net heat balance, positive values indicate net gain.

Data for the three conditions were compared using repeated measures analysis of variance for all the variables. A post hoc analysis for significant differences between treatments was accomplished using Tukey's post hoc test. Results are reported as mean \pm SD for absolute amounts, or mean (95\% confidence interval) for rates; $P<.05$ identified statistically significant differences.

\section{Results}

Seven subjects ( 2 female) were studied, with a mean \pm SD age of $29.3 \pm 3$ years, height $174.6 \pm 12 \mathrm{~cm}$, weight $80.9 \pm 16 \mathrm{~kg}$, body surface area $2.0 \pm 0.2 \mathrm{~m}^{2}$, and fat percentage $23.6 \% \pm 7 \%$.

\section{CORE TEMPERATURE}

Exit $\mathrm{T}_{\mathrm{co}}$ was $35.9 \pm 1{ }^{\circ} \mathrm{C}$. There were no significant between-condition differences in either core cooling rate or afterdrop amount or duration (Figure 2). The rewarming rate in the warm water $\left(6.1^{\circ} \mathrm{C} \cdot \mathrm{h}^{-1}, 95 \%\right.$ CI: 5.3-6.9) was significantly higher than in the other two conditions $\left(2.0^{\circ} \mathrm{C} \cdot \mathrm{h}^{-1}, 95 \%\right.$ CI: $1.2-2.8$ for shivering only, and $2.2^{\circ} \mathrm{C} \cdot \mathrm{h}^{-1}, 95 \% \mathrm{CI}$ : $1.4-3.0$ for Fluidotherapy; $\mathrm{n}=7 ; P<.01)$.

\section{AVERAGE SKIN TEMPERATURE AND HEAT FLUX}

During rewarming, average total skin temperature was lower for the shivering only condition $\left(24.6 \pm 1{ }^{\circ} \mathrm{C}\right)$ than for Fluidotherapy $\left(30.6 \pm 1{ }^{\circ} \mathrm{C}\right)$ and warm water $(29.5 \pm$ $\left.2^{\circ} \mathrm{C} ; P<.01\right)$. However, there were no differences between the Fluidotherapy and warm water conditions. This corresponded to a mean total heat flux for the shivering only condition (loss of $\sim 5 \mathrm{~W}$ ) that was significantly different than Fluidotherapy and warm 


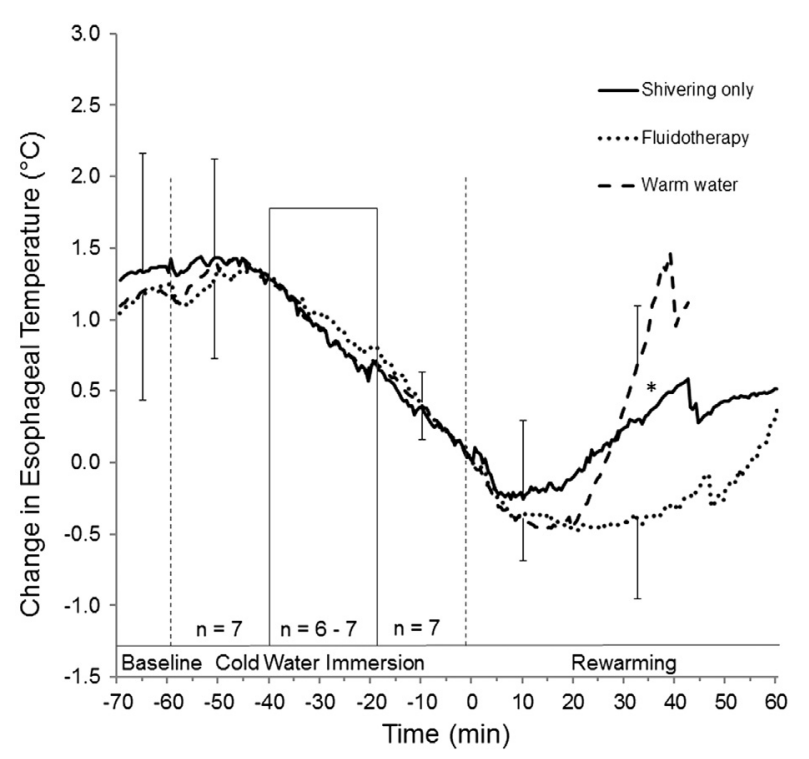

Figure 2. Mean change in esophageal temperature $\left({ }^{\circ} \mathrm{C}\right)$ during baseline, as long as 60 minutes of immersion in $8^{\circ} \mathrm{C}$ water, and as long as 60 minutes of rewarming in the shivering only condition (solid line), Fluidotherapy condition (dotted line), and warm water condition (dashed like). Time 0 minutes and temperature $0^{\circ} \mathrm{C}$ indicate exit from cold water (bars, SD). Six of the 7 subjects were immersed for the entire 60-minute cold water period in all conditions. The other subject reached the target esophageal temperature of $35^{\circ} \mathrm{C}$ within 38 to 46 minutes in all three immersions. To show what the whole group did at beginning and end of immersion, data for trials less than 60 minutes are presented for the first 20 minutes, with the remainder adjusted so that the exit time is lined up for everyone at time 0 . As a result, $\mathrm{n}=7$ for data from -60 to -40 minutes and from -18 to 0 minutes. During the period between -40 and -18 minutes, $\mathrm{n}=6$ to 7 . *Separates conditions that are significantly different from each other $(P<.01)$. Abrupt decreases near the end of rewarming periods are an artifact caused by termination of subjects who completed warming earlier than the others.

water (gain of more than $200 \mathrm{~W}$ ), with no difference between the latter two conditions $(P<.01)$ (Table 1$)$. Distal extremity skin temperatures and heat transfer were significantly different $(P<.01)$ between all conditions, with highest values for warm water immersion and lowest values for shivering only (Table 1).

\section{METABOLIC HEAT PRODUCTION}

During rewarming, the average metabolic heat production was significantly higher in the shivering only condition compared with the Fluidotherapy and warm water conditions $(P<.05)$ (Table 1; Figure 3, top).

\section{NET HEAT BALANCE}

During rewarming, the mean net heat gain during warm water immersion was significantly higher compared with shivering only $(P<.05)$ (Table 1 ; Figure 3 , bottom) but not Fluidotherapy.

\section{SUBJECTIVE EVALUATION}

Two subjects said that the warm water was too hot to get into initially, and another reported a feeling of "pins and needles"; the latter subject also felt Fluidotherapy was too warm. However, apart from the initial discomfort, warm water was the treatment of choice by 6 of the 7 subjects, whereas 1 preferred Fluidotherapy. Two subjects reported either back pain or that they did not like the forward-leaning position for Fluidotherapy; another subject made similar reports for all conditions.

\section{Discussion}

There was no significant difference in $\mathrm{T}_{\text {co }}$ afterdrop among the three conditions. These values $\left(0.6-0.7^{\circ} \mathrm{C}\right)$ are consistent with other rewarming conditions in which the shivering mechanism was intact. ${ }^{3,5,8}$ Fluidotherapy provided a rewarming rate similar to that of shivering only, and was consistent with other external rewarming modalities. $^{3,8}$

Consistent with previous studies, heat production and respiratory heat loss were increased in the shivering only condition. ${ }^{5,9}$ Shivering only provided a rewarming rate of $2.0^{\circ} \mathrm{C} \cdot \mathrm{h}^{-1}$, and in previous studies conducted, ${ }^{3,5,8}$ shivering by itself provided rewarming rates ranging from $2.4^{\circ} \mathrm{C} \cdot \mathrm{h}^{-1}$ to $3.5^{\circ} \mathrm{C} \cdot \mathrm{h}^{-1}$. However, it is important to note that the mean exit $\mathrm{T}_{\mathrm{co}}$ in the present study $\left(35.9^{\circ} \mathrm{C}\right)$ was higher than that in previous studies. ${ }^{3,5,8,9}$ As $\mathrm{T}_{\mathrm{co}}$ decreases, shivering heat production and rewarming rates increase.

When exit $T_{\text {co }}$ was lower, the rewarming curve was steeper initially, with high rewarming rates (3.0$3.5^{\circ} \mathrm{C} \cdot \mathrm{h}^{-1}$ ), with an inflection to a lower rewarming rate $\left(1.5-2.0^{\circ} \mathrm{C} \cdot \mathrm{h}^{-1}\right)$ at $\mathrm{T}_{\text {co }}$ approximately $36^{\circ} \mathrm{C}$. In the present study, there was no inflection during rewarming for shivering, similar to later rewarming $\left(>\mathrm{T}_{\mathrm{co}}\right.$ of $\left.36^{\circ} \mathrm{C}\right)$ in previous studies. In the present study, the highest rewarming rate and heat transfer with water immersion was consistent with previous studies. ${ }^{5}$

Fluidotherapy actually donated less heat than warm water for several reasons. First, the temperature difference between Fluidotherapy and warm water was only approximately $2^{\circ} \mathrm{C}$ because none of the subjects tolerated Fluidotherapy at $50^{\circ} \mathrm{C}$ (maximum was $46.1^{\circ} \mathrm{C}$ ). Second, the thermal conductivity of the fluidized cellulose bed is higher than air alone, but lower than water. Thus, the small temperature increase with Fluidotherapy $\left(46^{\circ} \mathrm{C}\right.$ vs $44^{\circ} \mathrm{C}$ ) was not enough to transfer more heat than the water. Third, although heat transfer was consistent over all immersed skin in warm water, it decreased proximally 
Table 1. Results of afterdrop, rewarming rate as well as heat production and transfer values by condition during rewarming

\begin{tabular}{|c|c|c|c|}
\hline Variable & Shivering only & $\begin{array}{l}\text { Fluidotherapy } \\
\left(46.1 \pm 1^{\circ} \mathrm{C}\right)\end{array}$ & $\begin{array}{l}\text { Warm water } \\
\left(44.1 \pm 1^{\circ} \mathrm{C}\right)\end{array}$ \\
\hline Afterdrop amount, ${ }^{\circ} \mathrm{C}$ & $0.6 \pm 0.4$ & $0.7 \pm 0.4$ & $0.6 \pm 0.4$ \\
\hline Afterdrop length $(\mathrm{n}=5)$, min & $24.9 \pm 17$ & $33.3 \pm 22$ & $23.8 \pm 11$ \\
\hline Rewarming rate (nadir to $35 \mathrm{~min}$ ), ${ }^{\circ} \mathrm{C} \cdot \mathrm{h}^{-1}$ & $2.0(1.2-2.8)$ & $2.2(1.4-3.0)$ & $6.1(5.3-6.9)^{a c}$ \\
\hline Mean metabolic heat production, $\mathrm{W}$ & $322 \pm 142$ & $166 \pm 42^{a}$ & $181 \pm 45^{a}$ \\
\hline Mean respiratory heat loss, $\mathrm{W}$ & $29 \pm 13$ & $15 \pm 4^{a}$ & $16 \pm 4^{a}$ \\
\hline Mean $\mathrm{T}_{\text {skinDistExt }}(5-35 \mathrm{~min}),{ }^{\circ} \mathrm{C}$ & $20.3 \pm 1$ & $33.9 \pm 2^{b}$ & $38.3 \pm 1^{b c}$ \\
\hline Mean $\mathrm{HF}_{\text {DistExt }}(5-35 \mathrm{~min}), \mathrm{W}$ & $-15 \pm 6$ & $-158 \pm 23^{b}$ & $-205 \pm 42^{b d}$ \\
\hline Mean $\mathrm{HF}_{\text {AntTor }}(5-35 \mathrm{~min}), \mathrm{W}$ & $8 \pm 9$ & $-27 \pm 16^{b}$ & $-6 \pm 14^{d}$ \\
\hline Mean $\mathrm{HF}_{\text {Total }}(5-35 \mathrm{~min}), \mathrm{W}$ & $5 \pm 23$ & $-215 \pm 38^{b}$ & $-233 \pm 70^{b}$ \\
\hline Mean net HB (5-35 min), W & $288 \pm 115$ & $367 \pm 47$ & $398 \pm 52^{a}$ \\
\hline
\end{tabular}

Values are mean $\pm \mathrm{SD}$ for amounts; mean $(95 \% \mathrm{CI})$ for rate.

${ }^{a}$ Different from shivering, $P \leq .05$.

${ }^{b}$ Different from shivering, $P \leq .01$.

${ }^{c}$ Different from Fluidotherapy, $P \leq .05$.

${ }^{d}$ Different from Fluidotherapy, $P \leq .01$.

$\mathrm{T}$, temperature; HF, heat flux (positive values indicate loss); skinDistExt, skin distal extremities; DistExt, distal extremities; AntTor, anterior torso; $\mathrm{HB}$, heat balance (positive values indicate gain).
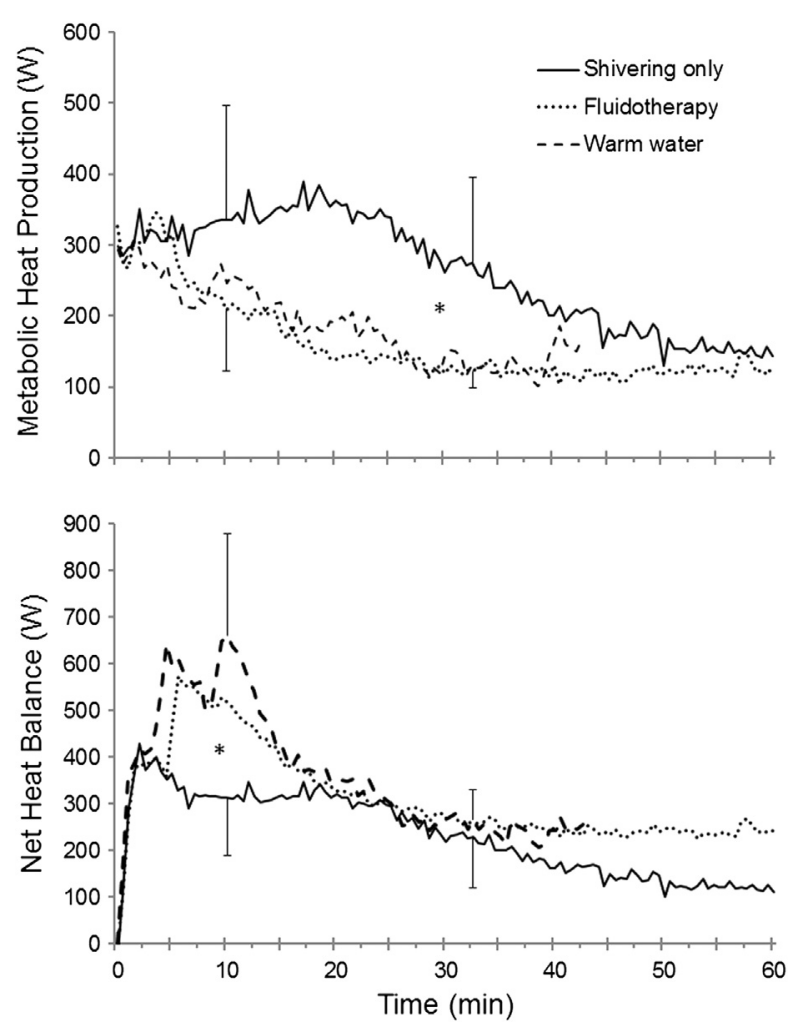

Figure 3. (Top panel) Metabolic heat production (W) and (bottom panel) net heat balance $(\mathrm{W})$ during 60 minutes of rewarming (bars, SD). *Separates conditions that are significantly different from each other $(P<.05)$. Solid lines, shivering only; dotted lines, Fluidotherapy; dashed lines, warm water. in immersed skin in Fluidotherapy (as indicated by skin redness). Finally, our warm water rewarming rate was lower than previously reported. ${ }^{5}$ This finding is consistent with the higher end cooling $\mathrm{T}_{\mathrm{co}}$ in this study $\left(35.9^{\circ} \mathrm{C}\right.$ vs $\left.34.3^{\circ} \mathrm{C}\right)$.

We do not consider that our sample size $(n=7)$ was a limitation of this study; this sample size provides enough power to reveal any clinically significant differences. Five subjects had high body fat, and exit $\mathrm{T}_{\mathrm{co}}$ did not reach the clinical threshold for hypothermia $\left(35^{\circ} \mathrm{C}\right)$. That did not limit our conclusions, as we have previously shown that in high-fat groups (with similar exit $\mathrm{T}_{\mathrm{co}}$ ), any intercondition differences are actually accentuated. ${ }^{10}$

\section{Conclusion}

Although Fluidotherapy did not rewarm subjects as quickly as warm water, it had the advantage over passive rewarming (shivering) of decreasing shivering metabolism, and presumably cardiovascular work. Because Fluidotherapy is more portable and technically simpler than warm water, it could be used for mild hypothermia. Neither extremity warming technique is advised for moderate to severe hypothermia owing to the patient's decreased physical capacity and potential loss of consciousness.

\section{Acknowledgments}

We would like to thank the Natural Sciences and Engineering Research Council of Canada for financially supporting 
this project, and the Faculty of Kinesiology and Recreation Management, University of Manitoba, for their financial support by FKRM Stipend and Graduate Research Assistantship. We would also like to thank our subjects for participating in the study. Finally, a special thanks to Jimmy Gazetis from DJO Global for lending the Fluidotherapy equipment to conduct the study.

\section{References}

1. Baumgartner EA, Belson M, Rubin C, Patel M. Hypothermia and other cold-related morbidity emergency department visits: United States, 1995-2004. Wilderness Environ Med. 2008;19:233-237.

2. Lundgren J, Henriksson O, Pretorius T, et al. Field torsowarming modalities: a comparative study using a human model. Prehosp Emerg Care. 2009;13:371-378.

3. Giesbrecht GG, Schroeder M, Bristow GK. Treatment of mild immersion hypothermia by forced-air warming. Aviat Space Environ Med. 1994;65:803-808.

4. Zafren K, Giesbrecht GG, Danzl DF, et al. Wilderness Medical Society hypothermia guidelines for the out-of- hospital evaluation and treatment of accidental hypothermia: 2014 update. Wilderness Environ Med. 2014;25 (Suppl):66-85.

5. Vanggaard L, Eyolfson D, Xu X, Weseen G, Giesbrecht GG. Immersion of distal arms and legs in warm water (AVA rewarming) effectively rewarms hypothermic humans. Aviat Space Environ Med. 1999;70:1081-1088.

6. Herrick R, Herrick S. Fluidotherapy. Clinical applications and techniques. Ala Med. 1992;61:20-25.

7. Borrell RM, Parker R, Henley EJ, Masley D, Repinecz M. Comparison of in vivo temperatures produced by hydrotherapy, paraffin wax treatment, and Fluidotherapy. Physical Ther. 1980;60:1273-1276.

8. Giesbrecht GG, Sessler DI, Mekjavic IB, Schroeder M, Bristow GK. Treatment of mild immersion hypothermia by direct body-to-body contact. J Appl Physiol. 1994;76: 2373-2379.

9. Giesbrecht GG, Bristow GK, Uin A, Ready AE, Jones RA. Effectiveness of three field treatments for induced mild (33.0 ${ }^{\circ}$ C) hypothermia. J Appl Physiol. 1987;63:2375-2379.

10. Giesbrecht GG, Bristow GK. Influence of body composition on rewarming from immersion hypothermia. Aviat Space Environ Med. 1995;66:1144-1150. 